\title{
Shared care obesity management in 3-10 year old children: 12 month outcomes of HopSCOTCH randomised trial
}

\author{
(c) $\frac{(1)(8)}{\mathrm{gY}_{\mathrm{Na}}}$ OPEN ACCESS
}

\author{
Melissa Wake paediatrician ${ }^{123}$, Kate Lycett research assistant ${ }^{23}$, Susan A Clifford research officer ${ }^{2}$, \\ Matthew A Sabin paediatric endocrinologist ${ }^{123}$, Jane Gunn professor ${ }^{4}$, Kay Gibbons dietitian ${ }^{12}$, \\ Cathy Hutton general practitioner ${ }^{4}$, Zoë McCallum paediatrician ${ }^{13}$, Sarah J Arnup biostatistician ${ }^{2}$, \\ Gary Wittert professor ${ }^{5}$
}

${ }^{1}$ Royal Children's Hospital, Parkville VIC 3052, Australia; ${ }^{2}$ Murdoch Childrens Research Institute, Parkville VIC 3052, Australia; ${ }^{3}$ University of Melbourne, Parkville VIC 3052, Australia; ${ }^{4}$ Department of General Practice, University of Melbourne, Parkville VIC 3052 , Australia; ${ }^{5}$ Discipline of Medicine, University of Adelaide, Adelaide, SA 5005, Australia

\begin{abstract}
Objective To determine whether general practice surveillance for childhood obesity, followed by obesity management across primary and tertiary care settings using a shared care model, improves body mass index and related outcomes in obese children aged 3-10 years.

Design Randomised controlled trial.

Setting 22 family practices (35 participating general practitioners) and a tertiary weight management service (three paediatricians, two dietitians) in Melbourne, Australia.

Participants Children aged 3-10 years with body mass index above the 95th centile recruited through their general practice between July 2009 and April 2010.

Intervention Children were randomly allocated to one tertiary appointment followed by up to 11 general practice consultations over one year, supported by shared care, web based software (intervention) or "usual care" (control). Researchers collecting outcome measurements, but not participants, were blinded to group assignment.
\end{abstract}

Main outcome measures Children's body mass index z score (primary outcome), body fat percentage, waist circumference, physical activity, quality of diet, health related quality of life, self esteem, and body dissatisfaction and parents' body mass index (all 15 months post-enrolment).

Results 118 (60 intervention, 56 control) children were recruited and 107 (91\%) were retained and analysed (56 intervention, 51 control). All retained intervention children attended the tertiary appointment and their general practitioner for at least one (mean 3.5 (SD 2.5, range 1-11)) weight management consultation. At outcome, children in the two trial arms had similar body mass index (adjusted mean difference -0.1 (95\% confidence interval -0.7 to $0.5 ; P=0.7)$ ) and body mass index $z$ score
(-0.05 (-0.14 to 0.03 ); $P=0.2)$. Similarly, no evidence was found of benefit or harm on any secondary outcome. Outcomes varied widely in the combined cohort (mean change in body mass index z score -0.20 (SD 0.25 , range $-0.97-0.47$ ); $26 \%$ of children resolved from obese to overweight and $2 \%$ to normal weight.

Conclusions Although feasible, not harmful, and highly rated by both families and general practitioners, the shared care model of primary and tertiary care management did not lead to better body mass index or other outcomes for the intervention group compared with the control group. Improvements in body mass index in both groups highlight the value of untreated controls when determining efficacy.

Trial registration Australian New Zealand Clinical Trials Registry ACTRN12608000055303.

\section{Introduction}

Rates of childhood obesity are at record high levels, ${ }^{1}$ with around $7 \%$ of 5-12 year olds having established obesity. ${ }^{23}$ These children are at heightened risk of obesity in adulthood, ${ }^{4}$ illnesses such as heart disease and diabetes, ${ }^{5}$ and psychological morbidity, ${ }^{6}$ all with associated excess healthcare costs. ${ }^{7}$ Long term weight related diseases can be prevented with an improvement in weight status ${ }^{8}$; however, despite the urgent need, ${ }^{9}$ effective, evidence based treatments for children remain elusive.

Although general paediatricians report competency in managing childhood obesity, ${ }^{10}$ few feel able to bring about change. Tertiary obesity clinics on the other hand report improvements in body mass index $\mathrm{z}$ score in most children, with a third achieving reductions associated with definite decreases in fat and risk 
factors for heart disease and diabetes. ${ }^{11-13}$ Such clinics can only see a small minority of obese children, however, and over time the caseload typically becomes skewed to adolescents with psychological and social problems. ${ }^{13}$

The recent Cochrane review of treatment of childhood obesity concluded that behavioural lifestyle interventions can produce a meaningful reduction in weight compared with standard care or self help. ${ }^{14}$ In many developed countries (including Australia), general practitioners are seen as central to such efforts, ${ }^{15}$ representing the only healthcare service that is universally accessible throughout childhood. General practitioners themselves consider that management of childhood obesity falls within their role. ${ }^{16}$ With training, they can report high comfort and competence in detecting and broaching this problem, which can in turn flow on into active management. ${ }^{17} 18$

Nevertheless, randomised trials comparing primary care weight management interventions with usual or no care have proved disappointing. ${ }^{19}$ For example, neither of the Live, Eat and Play (LEAP) or the High Five for Kids trials reported lasting benefits to body mass index from diet, physical activity, and sedentary behaviour counselling provided in primary care settings by general practitioners, paediatricians, or paediatric nurses..$^{182021}$ Furthermore, outside the research context, general practitioners typically measure and interpret body mass index infrequently, ${ }^{22}$ often under-diagnose overweight and obesity, ${ }^{22}$ have low confidence in managing overweight/obesity and achieving weight change, ${ }^{22} 23$ and only rarely treat obese children actively for their weight. ${ }^{24}$

A shared care model involving tertiary obesity specialists and general practitioners might combine "the best of both worlds" for greater success. Cochrane reviews of shared models of care for chronic conditions are mixed; Smith et al found insufficient evidence to support shared primary-specialist care, ${ }^{25}$ but Gruen et al reported that "specialist outreach can improve access, outcomes and service use, especially when delivered as part of a multifaceted intervention. ${ }^{, 26}$ More specifically, for obese adults attending a tertiary weight management clinic, shared care with general practitioners outperformed the specialist arm in short term (10 week) weight loss and dietary habits and achieved comparable six month weight loss. ${ }^{27}$ The only childhood trial so far published randomised obese 5-16 year olds to either shared care (a single tertiary care visit followed by nurse led primary care) or wholly tertiary care, achieving similar reductions in 12 month body mass index z scores of 0.17 and $0.15{ }^{28}$ However, lack of a true control group was a limitation, and the potential of shared care approaches remains to be confirmed.

This paper reports outcomes of a randomised controlled trial that aimed to determine whether, compared with non-intervention control children, a 12 month shared care obesity management intervention reduced body mass index $\mathrm{z}$ score (primary outcome) and improved body fat, waist circumference, physical activity, and quality of diet (secondary outcomes) 15 months post-enrolment and whether intervention children showed evidence of harm (for example, poorer health status, body satisfaction, or global self worth). We also evaluated the intervention's acceptability and feasibility to parents and general practitioners.

\section{Methods}

\section{Study design and setting}

HopSCOTCH (the Shared Care Obesity Trial in Children) was a randomised controlled trial conducted in general practices in metropolitan Melbourne (population 3.9 million), Australia. Methods are detailed in the published protocol ${ }^{29}$ and described briefly below; figure $1 \Downarrow$ summarises the design.

\section{General practitioner recruitment and education}

We recruited general practitioners through professional networks, personal invitation, or both; nine had participated in our previous LEAP trial. Of the 70 who expressed interest, 35 ultimately participated in 22 practices. Because HopSCOTCH aimed to test a shared care model as it might be rolled out in practice, we deliberately limited group training to one 2.5 hour evening group session. This introduced brief motivational interviewing and solution focused techniques, obesity management, measurement and interpretation of anthropometry, and supervised practice with the purpose designed shared care software.

General practitioners with intervention children received an additional 30 minute one on one software training session at their practice, supported by a two page quick reference software guide. Each practitioner used the software to work through a test patient with the HopSCOTCH research assistant to simulate a shared care appointment. Many practices subsequently received ad hoc "troubleshooting" visits to answer software related and other questions. Practice staff were trained in anthropometry to do the cross sectional survey. ${ }^{29}$

\section{Participant recruitment}

Practice staff invited children aged 3-10 years (up to but not including their 11th birthday) attending each practice to be weighed and measured to determine eligibility. They measured

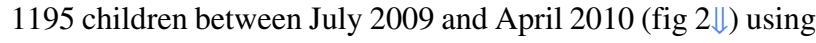
calibrated scales (model TITHD646, Tanita) and stadiometers (model IP0955, Invicta) provided for the study. With parents' assent, they forwarded contact details and the child's height and weight to the study team, from which the researchers calculated body mass index z scores and body mass index status according to the US Centers for Disease Control reference. ${ }^{30}$

Children were eligible if they were obese but not receiving an ongoing weight management programme. Exclusion criteria included a known endocrine or chromosomal cause for obesity, major health and developmental conditions, and insufficient English to comprehend sessions or complete questionnaires. Researchers phoned and then mailed an informed consent form and baseline questionnaire to parents of eligible children; on receipt, HopSCOTCH formally enrolled each child.

\section{Randomisation and blinding}

An independent research assistant allocated enrolled children to intervention or "usual care" (control) arms in a 1 to 1 ratio by using a concealed computerised random number sequence, stratified by general practitioner, pre-generated by a biostatistician not otherwise connected with HopSCOTCH. Research assistants blind to group allocation measured outcomes, but, once allocated, participants could not be blinded to group membership. Specialists and general practitioners were aware only of children in the intervention group.

\section{Intervention design and delivery}

Approximately two months after enrolment, intervention children attended a one hour appointment with a specialist tertiary weight management service at Melbourne's Royal Children's Hospital. Between November 2009 and July 2010, 
each child was seen by both a paediatrician and a dietitian provided with summarised child/family details pre-extracted from baseline questionnaire data. The clinicians took further history; did an examination and investigations to identify comorbidities of obesity; and discussed relevant dietary, physical activity, and family/child lifestyle changes. Before leaving, the family and clinicians agreed on an initial care plan and specific goals. Information from all these steps was entered into the shared care, web based software.

The research team then scheduled a "long" appointment (20-40 minutes, Medicare Australia Benefits Schedule 36) with the child's general practitioner, to be followed by regular four to eight weekly "standard" consultations (6-20 minutes, Medicare Benefits Schedule 23) to review lifestyle and body mass index progress, identify and solve problems, and set new goals by using brief solution focused techniques. Data from each appointment were entered into the shared care software. Six months after the original appointment, the specialist team accessed the software to review each child's progress and faxed a summary progress report to the general practitioner. The specialist team was available to the general practitioner on an as-needed basis via email or phone, with escalation back to the tertiary team available to all intervention children at any time.

\section{Shared care software}

The HopSCOTCH web based, shared care software was developed in collaboration with Pen Computer Systems Pty Ltd. General practitioners had access to the software through a pop-up sidebar, which communicated to a server at the Royal Children's Hospital to enable data sharing and focused communication. The HopSCOTCH software was separate from the practitioner's patient management system because the benefits of data integration did not outweigh the technical risks and financial costs. The software was designed to provide collaboration and communication between the specialists and general practitioners, a structured yet efficient approach to weight management care, and a mechanism for joint recording and tracking of progress. General practitioners with intervention children were emailed a web link and detailed instructions to download the software.

The software enabled a structured intervention at each consultation for each visit, comprising five standardised sequential steps: recording anthropometry; reviewing change in body mass index, using an online chart to plot and track body mass index visually over time against centile charts; assessing and tracking progress and motivation; reviewing the care plan (for example, identifying problems and revising goals); and providing educational resources.

\section{Usual care}

Participants in the usual care (control) arm were free to seek assistance from their general practitioner or from any other service.

\section{Measures}

Table $1 \Downarrow$ describes the outcome measures. Baseline data came from body mass index ascertainment records and parents' questionnaires. Additional baseline adiposity measures (percentage body fat, waist circumference, and waist to height ratio) were available for the intervention group from their initial clinic visit. We present these to allow readers to better understand the level of adiposity in our sample, assuming that (owing to randomisation) the control children would have been balanced on these variables. Outcome data were collected during a home visit between February and July 2011, after which we audited general practice patients' records to determine compliance (how often intervention children saw their practitioner) and contamination (whether weight management was discussed for control children).

\section{Sample size}

Allowing for $10 \%$ loss to follow-up, we aimed to recruit 172 children. This would provide $80 \%$ power to detect a mean difference of 0.3 body mass index z score units at 15 months (comparable to published mean changes seen from specialist obesity clinics ${ }^{13}$ ) between arms at the $5 \%$ (two sided) level of significance.

\section{Potential confounders}

Potential a priori confounders were child's sex and age in years at randomisation and neighbourhood socioeconomic disadvantage score measured by the census based Socio-Economic Indexes for Areas Disadvantage Index for the child's postcode of residence (national mean 1000, SD 100; higher scores reflect greater advantage). ${ }^{31}$

\section{Analyses}

We analysed data by using the intention to treat principle with Stata 11.2 software. Linear (quantitative outcomes) and logistic (dichotomous outcomes) regressions were fitted for unadjusted models and models adjusted for the potential confounders, raw baseline body mass index (except body mass index z score analyses, which were adjusted for baseline $\mathrm{z}$ score), and the baseline value of the outcome measure where available. Parental body mass index outcomes were further adjusted for parent's age at randomisation.

To allow for within participant correlation in the four day food diary, the diet outcome regression analyses were fitted with random intercept models using maximum likelihood estimation. ${ }^{32}$ We analysed the six body and global self esteem items as a multivariate outcome. We estimated the odds ratio (population averaged) of a positive response by using generalised estimating equations fit with an exchangeable correlation structure to allow for within participant correlation. ${ }^{33}$

Finally, sensitivity analyses examined whether allowing for a correlation between siblings or between children seen by the same general practitioner affected the standard error of the outcomes or whether controlling for parents' body mass index, time lapsed, or number of visits affected outcomes. As results were virtually identical, we report the main analyses here.

\section{Results}

\section{Baseline characteristics and trial flow}

The final sample comprised 118 children (62 intervention, 56] control) because, once the participating practices reached saturation, reaching our desired sample size of 172 children was impossible. Figure $2 \Downarrow$ shows that, of the 118 eligible children enrolled who provided baseline data, 107 (91\%) contributed outcome data. The trial arms were similar at baseline (table $2 \Downarrow$ ), as were those children retained and lost to follow-up. Additional information from the specialist obesity visit (intervention group only) included percentage body fat (mean 32.6 (SD 6.1)), waist circumference (mean $73.9(12.7) \mathrm{cm}$ ), and waist to height ratio (mean $0.57(0.1)$ ). 


\section{Outcomes}

Children were assessed on average 14.8 (1.9) months post-enrolment, 13.5 (1.5) months post-randomisation, and (for the intervention children) 12.7 (1.5) months post-specialist visit, to allow for the full 12 months' follow-up in the intervention group. The two groups were similar in age at follow-up (intervention 8.5 (2.3), controls 8.4 (2.2) years old).

The intervention had little discernible effect on any primary or secondary outcome (table $3 \Downarrow$ ). As expected with age, raw body mass index rose over the 15 month period (mean change: intervention 0.78 (1.79), control $0.96(1.50)$ ), but body mass index z score fell slightly (mean change: intervention -0.22 (0.25), control $-0.18(0.25)$ ). Thus outcomes varied widely in the combined cohort (mean change in body mass index $\mathrm{z}$ score $-0.20(0.25)$, range $-0.97-0.47) ; 28 / 106(26 \%)$ of children resolved to overweight and 2/106 (2\%) to normal weight.

\section{Harm}

We found little evidence that the intervention was harmful in terms of health related quality of life, body and global self-esteem, and body dissatisfaction (table $3 \Downarrow$ ). Only 6/45 (13\%) intervention and 6/43 (14\%) control parents perceived that being told their child was obese negatively affected their child's feelings, and fewer than $10 \%$ of intervention parents reported negative effects from the specialist and general practitioner visits.

\section{Software implementation}

Despite a full year of development and piloting to make the software user friendly, only 12 of the 30 general practitioners with intervention children attempted to install it themselves using the emailed web link, and only four were successful. The other 26 installations required visits from researchers; nine also required support from an external developer. Computers with slow processing units and poor internet connections meant that seven general practitioners never got functional software; they used a structured paper version that was faxed between the research team and general practitioner after each appointment to track progress instead. Nevertheless, 23 (77\%) general practitioners persisted with the software, and the paper version ensured the integrity of the structured intervention for the remaining seven. Software users saw intervention children more often than did general practitioners using the paper version (on average $3.5 \vee 2.5$ times).

\section{Acceptability/feasibility}

Two intervention families withdrew on allocation; all others attended the specialist visit and at least one general practice appointment (mean 3.6 (SD 2.4, range 1-11) visits). During the trial, seven children (six intervention, one control) were referred back to the specialist team, although only four families chose to attend. The great majority of parents thought that both the specialist clinicians and general practitioners understood their family's challenges, understood how to implement the intervention goals, and felt confident that the intervention would make a difference to the child's weight/lifestyle (table $4 \Downarrow$ ).

Similarly, most general practitioners found the general shared care approach helpful, along with shared care components such as the specialist management plan and ongoing access to specialists.

\section{Discussion}

This shared care model of primary and tertiary management, although feasible, not harmful, and highly rated by both families and general practitioners, had no beneficial effect on body mass index outcomes in obese 3-10 year olds compared with the control group.

\section{Strengths and limitations of study}

Strengths of the study include the randomised design, blind outcome measurement, high uptake and retention rates, follow-up for a full 12 months from the start of the intervention, and the positive feedback about the shared care process. All intervention children attended the specialist and, on at least one occasion, the general practitioner. The practices from which children were recruited spanned a broad socioeconomic distribution. A further strength is the high quality anthropometric, body fat, and physical activity measurements and validated questionnaires; the dietary measure was more open to desirability bias, possibly accounting for it being the only measure to show a weak benefit.

Limitations of the study must also be considered. Although we recruited only 118 of the desired sample size of 172 children, the findings were robust and the $95 \%$ confidence intervals did not suggest clinically meaningful benefits. The self selected nature of the general practitioners and families and the non-blinding of families seem unlikely to have affected generalisability given the null outcomes.

More important in our view is the possibility that the intervention may have been insufficiently intensive or skilled to change body mass index trajectories. Firstly, we asked families to attend the obesity specialist team only once, given the scarcity of this resource in many jurisdictions and the distance many families would need to travel unless outreach was available. Secondly, families then attended their general practitioner on average only 3.5 (range 1-11) times over the ensuing year, rather than our recommended 5-11 visits (that is, every 4-8 weeks). Post hoc analyses, however, showed no relation between number of visits and body mass index outcome. Thirdly, although the general practitioners endorsed the software's high level of functionality under our optimal training conditions, it was more challenging in the field, reflecting both technological and end user difficulties that may have further compromised the time available for and the quality of the therapeutic interaction. Finally, we provided only basic training in obesity management, opting instead for the model we thought was most likely to operate in the "real world"- -specialists working with generalists who, although highly skilled clinicians, are not specifically trained in childhood obesity.

\section{Interpretation in light of other studies}

Previous primary care interventions have also been ineffective in reducing body mass index compared with true control (no intervention or usual care) children. ${ }^{20}{ }^{21}$ A systematic review of general practice and uncontrolled tertiary obesity studies suggest that more intensive programmes may be more successful $1^{35}$; for instance, the top five performers of 129 German paediatric obesity clinics provided the most intensive intervention (on average 17 hours per child over two years). ${ }^{36}$ A more intensive shared care intervention might thus be more successful in reducing gain in body mass index than was HopSCOTCH, although covering all the factors mentioned above would be resource intensive in terms of both technical and personnel support. 
Of note, mean body mass index $\mathrm{z}$ score fell by around 0.2 in both groups, with more than a quarter of children ceasing to be obese regardless of intervention. This is consistent with reductions in non-intervention arms of previous child obesity trials including the LEAP1 (body mass index $\mathrm{z}$ score reduction $-0.04)$, LEAP2 $(-0.14)$, and SCOTT $(-0.19)^{34}$ trials. Our controls received, and largely reported seeking, no additional help, giving us confidence that inadvertent active intervention (contamination) was not the reason for the observed changes. This leaves open the possibilities of regression to the mean, with a greater natural resolution of obesity than is usually acknowledged; the recruitment process (being made aware of the child's obesity, entering the trial, and completing the questionnaires) creating an intervention in itself, a notion that has been both supported and not supported in studies in which parents were notified of a child's high body mass index ${ }^{37} 38$; and the Hawthorne effect. We have no way of knowing if any of these operated here. Interestingly, the mean reduction in body mass index z score in our controls exceeded those reported in the previous trial comparing tertiary only care $(-0.15)$ with shared tertiary-primary care $(-0.17),{ }^{28}$ calling into question its conclusions regarding likely efficacy.

\section{Conclusions}

Although feasible, not harmful, and highly rated, this primary-tertiary shared care model did not benefit body mass index outcomes in obese 3-10 year olds over the ensuing year. Shared care approaches to managing childhood obesity might be effective with greater training and resourcing, but, as this would require a very substantial healthcare investment, such approaches should be rigorously trialled before wide adoption.

We thank all the children and parents; paediatrician Michele Campbell and dietitian Elisha Matthews who, along with MAS, KG, and ZM, provided the specialist weight management service; general practitioners and practice staff; and research assistants Louise Canterford, Megan Mathers, Caroline Bambrick, Natalie de Bono, Melissa Bourchier, Fari Koeman, and Elissa York. We also gratefully acknowledge the input and support of Pen Computer Systems and Michael Stringer of Knowsys in developing, deploying, and managing the shared care software.

Contributors: MW, JG, KG, GW, and MAS conceived HopSCOTCH, obtained funding, and directed the study. SC carried out the analyses with SA. MW, SC, and KL wrote the paper, with critical input from the other authors. MW is the guarantor.

Funding: HopSCOTCH was funded by the Australian National Health and Medical Research Council (NHMRC Priority Driven Research Grant 491212). MW was part funded by NHMRC Population Health Career Development Grants 284556 and 546405 and MAS by NHMRC Professional Training Fellowship 1012201. Murdoch Childrens Research Institute is supported by the Victorian Government's Operational Infrastructure Support Program.

Competing interests: All authors have completed the ICMJE uniform disclosure form at www.icmje.org/coi_disclosure.pdf (available on request from the corresponding author) and declare: MW, KL, MAS, JG, KG, CH, ZM, SC, and GW have support from the Australian National Health and Medical Research Council (NHMRC) for the submitted work; no relationships with any companies that might have an interest in the submitted work in the previous three years; no non-financial interests that may be relevant to the submitted work.

Ethical approval: The project was approved by the Royal Children's Hospital Ethics in Human Research Committee (HREC 280178) and the University of Melbourne Human Research Ethics Committee (0827435).

Data sharing: No additional data available.
1 Olds T, Maher C, Zumin S, Peneau S, Lioret S, Castetbon K, et al. Evidence that the prevalence of childhood overweight is plateauing: data from nine countries. Int $J$ Pediat Obes 2011;6:342-60.

2 Australian Bureau of Statistics. National health survey: summary of results, 2007 - 2008. ABS, 2009.

3 Australian Bureau of Statistics. Population by age and sex, Australian states and territories. Table 9. Estimated resident population by single year of age. 2007. www.abs.gov.au/ AUSSTATS/abs@.nsf/DetailsPage/3201.0Jun\%202007?OpenDocument.

4 Singh AS, Mulder C, Twisk JW, van Mechelen W, Chinapaw MJ. Tracking of childhood overweight into adulthood: a systematic review of the literature. Obes Rev 2008;9:474-88.

5 Reilly JJ, Kelly J. Long-term impact of overweight and obesity in childhood and adolescence on morbidity and premature mortality in adulthood: systematic review. Int $J$ Obes (Lond) 2011;35:891-8.

6 Anderson SE, Cohen P, Naumova EN, Jacques PF, Must A. Adolescent obesity and risk for subsequent major depressive disorder and anxiety disorder: prospective evidence. Psychosom Med 2007;69:740-7.

7 Au N. The health care cost implications of overweight and obesity during childhood. Health Serv Res 2012;47:655-76.

8 Juonala M, Magnussen CG, Berenson GS, Venn A, Burns TL, Sabin MA, et al. Childhood adiposity, adult adiposity, and cardiovascular risk factors. N Engl J Med 2011;365:1876-85.

9 Rocchini AP. Childhood obesity and coronary heart disease. N Engl J Med 2011;365:1927-9.

10 Wake M, Campbell MW, Turner M, Price A, Sabin MA, Davis E, et al. How training affects Australian paediatricians' management of obesity. Arch Dis Child 2013;98:3-8.

11 Hunt LP, Ford A, Sabin MA, Crowne EC, Shield JPH. Clinical measures of adiposity and percentage fat loss: which measure most accurately reflects fat loss and what should we aim for? Arch Dis Child 2007:92:399-403.

12 Reinehr T, Andler W. Changes in the atherogenic risk factor profile according to degree of weight loss. Arch Dis Child 2004;89:419-22.

13 Sabin MA, Ford A, Hunt L, Jamal R, Crowne EC, Shield JP. Which factors are associated with a successful outcome in a weight management programme for obese children? $J$ Eval Clin Pract 2007;13:364-8.

14 Oude Luttikhuis H, Baur L, Jansen H, Shrewsbury VA, O'Malley C, Stolk RP, et al. Interventions for treating obesity in children. Cochrane Database Syst Rev 2009;(1):CD001872.

15 National Health and Medical Research Council. Clinical practice guidelines for the management of overweight and obesity in children and adolescents. NHMRC, 2003.

16 Waters EB, Haby MM, Wake M, Salmon LA. Public health and preventive healthcare in children: current practices of Victorian GPs and barriers to participation. Med J Aust 2000;173:68-71.

17 Gerner B, Sanci L, Cahill H, Ukoumunne OC, Gold L, Rogers L, et al. Using simulated patients to develop doctors' skills in facilitating behaviour change: addressing childhood obesity. Med Educ 2010;44:706-15.

18 McCallum Z, Wake M, Gerner B, Baur LA, Gibbons K, Gold L, et al. Outcome data from the LEAP (Live, Eat and Play) trial: a randomized controlled trial of a primary care intervention for childhood overweight/mild obesity. Int J Obes (Lond) 2007;31:630-6.

19 Whitlock EP, Williams SB, Gold R, Smith PR, Shipman SA. Screening and interventions for childhood overweight: a summary of evidence for the US Preventive Services Task Force. Pediatrics 2005;116(1 suppl):e125-44.

20 Wake M, Baur LA, Gerner B, Gibbons K, Gold L, Gunn J, et al. Outcomes and costs of primary care surveillance and intervention for overweight or obese children: the LEAP 2 randomised controlled trial. BMJ 2009;339:b3308.

21 Taveras EM, Gortmaker SL, Hohman KH, Horan CM, Kleinman KP, Mitchell K, et al. Randomized controlled trial to improve primary care to prevent and manage childhood obesity: the high five for kids study. Arch Pediatr Adolesc Med 2011;165:714-22.

22 Gerner B, McCallum Z, Sheehan J, Harris C, Wake M. Are general practitioners equipped to detect child overweight/obesity? Survey and audit. J Paediatr Child Health 2006;42:206-11.

23 Dettori $\mathrm{H}$, Elliott $\mathrm{H}, \mathrm{H}$ Horn J, Leong $\mathrm{G}$. Barriers to the management of obesity in children-a cross sectional survey of GPs. Aust Fam Physician 2009;38:460-4.

24 Cretikos MA, Valenti L, Britt HC, Baur LA. General practice management of overweight and obesity in children and adolescents in Australia. Med Care 2008;46:1163-9.

25 Smith SM, Allwright S, O'Dowd T. Effectiveness of shared care across the interface between primary and specialty care in chronic disease management. Cochrane Database Syst Rev 2007;(3):CD004910.

26 Gruen R, Weeramanthri T, Knight S, Bailie R. Specialist outreach clinics in primary care and rural hospital settings. Cochrane Database Syst Rev 2004;(1):CD003798.

27 Richman RM, Webster P, Salgo AR, Mira M, Steinbeck KS, Caterson ID. A shared care approach in obesity management: the general practitioner and a hospital based service. Int J Obes Relat Metab Disord 1996;20:413-9.

28 Banks J, Sharp DJ, Hunt LP, Shield JPH. Evaluating the transferability of a hospital-based childhood obesity clinic to primary care: a randomised controlled trial. Br J Gen Pract 2012;62:18-9.

29 Wake M, Lycett K, Sabin MA, Gunn J, Gibbons K, Hutton C, et al. A shared-care model of obesity treatment for 3-10 year old children: protocol for the HopSCOTCH randomised controlled trial. BMC Pediatr 2012;12:39.

30 Kuczmarski RJ, Ogden CL, Grummer-Strawn LM, Flegal KM, Guo SS, Wei R, et al. CDC growth charts: United States. Adv Data 2000 Jun 8(314):1-27.

31 Australian Bureau of Statistics. Socio-economic indexes for areas (SEIFA) -technical paper 2006. ABS, 2008.

32 Hanley JA, Negassa A, Edwardes MD, Forrester JE. Statistical analysis of correlated data using generalized estimating equations: an orientation. Am J Epidemiol 2003;157:364-75.

33 Goldstein H. Multilevel statistical models. 2nd ed. Arnold, 1995.

34 Hughes AR, Stewart L, Chapple J, McColl JH, Donaldson MD, Kelnar CJ, et al. Randomized, controlled trial of a best-practice individualized behavioral program for treatment of childhood overweight: Scottish Childhood Overweight Treatment Trial (SCOTT). Pediatrics 2008;121:e539-46.

35 Sargent GM, Pilotto LS, Baur LA. Components of primary care interventions to treat childhood overweight and obesity: a systematic review of effect. Obes Rev 2011;12:e219-35.

36 Reinehr T, Widhalm K, l'Allemand D, Wiegand S, Wabitsch M, Holl RW, et al. Two-year follow-up in 21,784 overweight children and adolescents with lifestyle intervention. Obesity (Silver Spring) 2009;17:1196-9.

37 Meriaux BG, Hellstrom AL, Marild S. Identification and follow-up of obesity in ten-year-old school children. Int J Pediatr Obes 2008;3:102-8. 


\section{What is already known on this topic}

Only a small minority of obese children can access tertiary weight management clinics

Shared tertiary-general practitioner care is feasible for a range of conditions and could enhance access to care for obese children, but its effectiveness has not been tested

\section{What this study adds}

A 12 month, shared care obesity management programme for 3-10 year olds was feasible, not harmful, and acceptable to healthcare providers and families but did not improve children's body mass index relative to untreated controls

Body mass index z score in many children improved in both groups, highlighting the value of untreated controls when determining efficacy

A more intensive shared care intervention might be more successful, but the required technical and personnel support would probably preclude wide dissemination in general practice

38 Madsen KA. School-based body mass index screening and parent notification: a statewide natural experiment. Arch Pediatr Adolesc Med 2011;165:987-92.

39 Perera R, Heneghan C, Yudkin P. A graphical method for depicting randomised trials of complex interventions. BMJ 2007;334:127-9.

40 Schaefer F, Georgi M, Zieger A, Scharer K. Usefulness of bioelectric impedance and skinfold measurements in predicting fat-free masss derived from total-body potassium in children. Pediatr Res 1994;35:617-24.

41 Varni JW, Burwinkle TM, Seid M, Skarr D. The PedsQL (TM) 4.0 as a pediatric population health measure: feasibility, reliability, and validity. Ambul Pediatr 2003;3:329-41.

42 Collins ME. Body figure perceptions and preferences among preadolescent children. Int J Eat Disord 1991;102:199-208.

\section{Accepted: 8 May 2013}

\section{Cite this as: BMJ 2013;346:f3092}

This is an Open Access article distributed in accordance with the Creative Commons Attribution Non Commercial (CC BY-NC 3.0) license, which permits others to distribute, remix, adapt, build upon this work non-commercially, and license their derivative works on different terms, provided the original work is properly cited and the use is non-commercial. See: http://creativecommons.org/licenses/by-nc/3.0/. 


\section{Tables}

\section{Table 1| Primary and secondary outcome measures for HopSCOTCH trial}

\begin{tabular}{|c|c|c|c|c|}
\hline & \multicolumn{2}{|c|}{ Time point } & \multirow[b]{2}{*}{ Measure } & \multirow[b]{2}{*}{ Additional information } \\
\hline & Baseline & Outcome & & \\
\hline \multicolumn{5}{|l|}{ Primary outcome } \\
\hline $\begin{array}{l}\text { Child body mass } \\
\text { index z score }\end{array}$ & Yes & Yes & $\begin{array}{l}\text { Portable rigid stadiometer (model } \\
\text { IP0955, Invicta, Leicester, UK); } \\
\text { measured. Calibrated digital scale } \\
\text { (model ITHD646,Tanita, Toyko, } \\
\text { Japan); measured }\end{array}$ & $\begin{array}{l}\text { Height measured twice and average used; if values differed by }>0.5 \mathrm{~cm} \text {, } \\
\text { third measurement taken and average of two closest values used. Weight, } \\
\text { while wearing light clothing, measured once at baseline and twice at } \\
\text { outcome. Average weight used at outcome; if values differed by } \geq 0.2 \mathrm{~kg} \text {, } \\
\text { third measure taken and average of two closest values used. Body mass } \\
\text { index calculated as weight }(\mathrm{kg}) /\left(\text { height }(\mathrm{m})^{2}\right) ; z \text { score calculated according } \\
\text { to US Centers for Disease Control reference values, }{ }^{30} \text { using Stata "zanthro" } \\
\text { function }\end{array}$ \\
\hline
\end{tabular}

\section{Secondary outcomes}

\begin{tabular}{llll}
\hline Waist circumference & Yes $^{*}$ & Yes & $\begin{array}{l}\text { Lufkin Executive Steel Tape } \\
\text { (W606PM); measured }\end{array}$ \\
\hline Body fat (\%) & Yes $^{*}$ & Yes & $\begin{array}{l}\text { Tanita Digital Body Composition } \\
\text { Monitor (BC-351) })^{40} \text {; measured }\end{array}$ \\
\hline Diet quality & No & Yes & 4 day food diary; parent report
\end{tabular}

Average of two waist measurements; if they differed by $\geq 1 \mathrm{~cm}$, third measurement taken and mean of two closest used. Waist to height ratio calculated as waist circumference $(\mathrm{cm}) /$ height $(\mathrm{cm})$

Average of two body percentage fat measurements

Parents reported child's consumption of each of 17 food and drink items $(0,1,2,>2$ times) for two weekdays and two weekend days. Dichotomous ("yes," "no") variables derived for five "healthy behaviours" (high fruit, vegetables, and water; low fatty/sugary foods and non-diet sweet drinks) for each day. Number of healthy behaviours per day summed to give score between 0 and 5 (higher score indicates more healthy behaviour)

\begin{tabular}{lll}
\hline Physical activity No Nos $\quad$ Actical Accelerometer (Mini Mitter); \\
measured
\end{tabular}

Worn for 7 full days; $\geq 5$ valid days required. Valid days had $\geq 10$ hours of non-missing data between 6 am and $11 \mathrm{pm}$. Missing data were segments with $\geq 20$ minutes of consecutive " 0 " counts, or counts $>0$ that were constant for $\geq 10$ minutes. Outcomes across all valid days: mean activity counts/min and $\%$ time spent in moderate to vigorous physical activity

\begin{tabular}{|c|c|c|c|c|}
\hline $\begin{array}{l}\text { Health related quality } \\
\text { of life (health status) }\end{array}$ & Yes & Yes & $\begin{array}{l}\text { Paediatric quality of life inventory } \\
\text { (PedsQL } 4.0) \text {; self report and parent } \\
\text { proxy versions }{ }^{41}\end{array}$ & $\begin{array}{l}\text { Parent completed } 23 \text { item scale that yields total, physical summary, and } \\
\text { psychosocial summary scores, each with possible range of } 0-100 \text { (100=best } \\
\text { possible health); quantitative variable }\end{array}$ \\
\hline Body dissatisfaction & No & Yes & $\begin{array}{l}\text { Body figure perception questionnaire; } \\
\text { self report }{ }^{42}\end{array}$ & $\begin{array}{l}\text { Child picture scale of } 1-7 \text { ( } 1=\text { underweight, } 7=\text { obese) from which child picks } \\
\text { perceived and ideal selves. "Perceived" minus "ideal" self yields discrepancy } \\
\text { index, with positive and negatives scores representing desires to be thinner } \\
\text { and fatter, respectively }\end{array}$ \\
\hline $\begin{array}{l}\text { Physical appearance } \\
\text { and self worth }\end{array}$ & No & Yes & $\begin{array}{l}\text { Modified from Harter's perceived } \\
\text { competence scale; self report }\end{array}$ & $\begin{array}{l}\text { Six pairs of statements with binary response format; children choose } \\
\text { statement from each pair that is closest to their competence. Each of six } \\
\text { responses is then coded as being either "positive/better perception" or } \\
\text { "negative/worse perception". Six responses analysed as single outcome } \\
\text { (\% positive responses and population averaged odds ratio of positive } \\
\text { response) }\end{array}$ \\
\hline $\begin{array}{l}\text { Parent body mass } \\
\text { index }\end{array}$ & Yes & Yes & $\begin{array}{l}\text { Height and weight measured (using } \\
\text { stadiometer and scales described } \\
\text { above) and self report }\end{array}$ & $\begin{array}{l}\left.\text { Baseline parent body mass index (weight }(\mathrm{kg}) / \text { height }(\mathrm{m})^{2}\right) \text { calculated from } \\
\text { height and weight values reported by responding parent. Outcome parent } \\
\text { body mass index calculated from measured height and weight when } \\
\text { available, otherwise from values reported by responding parent }\end{array}$ \\
\hline
\end{tabular}

*Data collected only from intervention arm children at tertiary clinic appointment ("baseline"). 
Table 2| Baseline sample characteristics by trial arm and by participation status at outcome

\begin{tabular}{|c|c|c|c|c|c|c|c|c|}
\hline \multirow[b]{3}{*}{ Characteristic } & \multicolumn{4}{|c|}{ Trial arm } & \multicolumn{4}{|c|}{ Retention to outcome } \\
\hline & \multicolumn{2}{|c|}{ Intervention } & \multicolumn{2}{|c|}{ Control } & \multicolumn{2}{|c|}{ Retained } & \multicolumn{2}{|c|}{ Lost } \\
\hline & No & Value $^{*}$ & No & Value $^{*}$ & No & Value* & No & Value $^{*}$ \\
\hline \multicolumn{9}{|l|}{ Child: } \\
\hline Age (years) & 62 & $7.2(2.3)$ & 56 & $7.4(2.2)$ & 107 & $7.3(2.2)$ & 11 & $7.7(2.7)$ \\
\hline Male sex, No (\%) & 62 & $31(50)$ & 56 & $33(59)$ & 107 & $57(53)$ & 11 & $7(64)$ \\
\hline Body mass index & 62 & $22.3(2.7)$ & 56 & $22.8(3.6)$ & 107 & $22.5(3.2)$ & 11 & $22.7(3.1)$ \\
\hline Body mass index $z$ score & 62 & $2.2(0.5)$ & 56 & $2.1(0.3)$ & 107 & $2.2(0.4)$ & 11 & $2.2(0.5)$ \\
\hline Family disadvantage index & 62 & $1029(65.7)$ & 56 & $1030(45.3)$ & 107 & $1030(56.8)$ & 11 & $1022(57.9)$ \\
\hline \multicolumn{9}{|l|}{ Mother: } \\
\hline Body mass index $†$ & 55 & $26.9(5.7)$ & 44 & $28.0(7.1)$ & 90 & $27.4(6.5)$ & 9 & $26.8(5.4)$ \\
\hline Overweight or obese, No (\%) & 55 & $28(51)$ & 44 & $26(59)$ & 90 & $48(53)$ & 9 & $6(67)$ \\
\hline \multicolumn{9}{|l|}{ Father: } \\
\hline Body mass index $†$ & 49 & $27.8(6.9)$ & 37 & $29.8(4.9)$ & 79 & $30.1(6.2)$ & 7 & $26.4(2.6)$ \\
\hline Overweight or obese, No (\%) & 49 & $39(80)$ & 37 & $31(84)$ & 79 & $66(84)$ & 7 & $4(57)$ \\
\hline
\end{tabular}

*Values are mean (SD) unless otherwise indicated.

†Parent's body mass index calculated from height and weight values reported by responding parent. 


\begin{tabular}{|c|c|c|c|c|c|c|c|c|}
\hline \multicolumn{9}{|c|}{ Table 3| Outcomes by trial arm } \\
\hline \multirow[b]{3}{*}{ Outcome } & \multicolumn{4}{|c|}{ Trial arm } & \multicolumn{4}{|c|}{ Difference (intervention-control) } \\
\hline & \multicolumn{2}{|c|}{ Intervention } & \multicolumn{2}{|c|}{ Control } & \multicolumn{2}{|c|}{ Unadjusted } & \multicolumn{2}{|c|}{ Adjusted } \\
\hline & No & Valuet & No & Valuet & Statisticł & $P$ value & Statistic‡ & $P$ value \\
\hline \multicolumn{9}{|l|}{ Child } \\
\hline $\begin{array}{l}\text { Body mass index } \\
\text { (BMI) }\end{array}$ & 56 & $23.2(3.8)$ & 49 & $23.6(4.6)$ & $-0.4(-2.0$ to 1.2$)$ & 0.6 & $-0.1(-0.7$ to 0.5$)$ & 0.7 \\
\hline BMI z score & 56 & $2.0(0.5)$ & 49 & $2.0(0.4)$ & $\begin{array}{c}-0.01(-0.20 \text { to } \\
0.18)\end{array}$ & 0.9 & $\begin{array}{c}-0.05(-0.14 \text { to } \\
0.03)\end{array}$ & 0.2 \\
\hline Total body fat (\%) & 56 & $32.9(7.2)$ & 48 & $34.2(6.2)$ & $-1.3(-3.9$ to 1.4$)$ & 0.3 & $-0.9(-2.6$ to 0.8$)$ & 0.3 \\
\hline $\begin{array}{l}\text { Waist circumference } \\
(\mathrm{cm})\end{array}$ & 56 & $75.6(13.0)$ & 49 & $77.9(13.6)$ & $-2.3(-7.5$ to 2.8$)$ & 0.4 & $-1.7(-4.1$ to 0.6$)$ & 0.1 \\
\hline \multicolumn{9}{|l|}{$\begin{array}{l}\text { Physical activity } \\
\text { (accelerometry): }\end{array}$} \\
\hline $\begin{array}{l}\text { Mean counts per } \\
\text { minute }\end{array}$ & 48 & $332(113)$ & 44 & $309(106)$ & $\begin{array}{l}23.1(-22.5 \text { to } \\
68.7)\end{array}$ & 0.3 & $\begin{array}{l}25.1(-17.6 \text { to } \\
67.8)\end{array}$ & 0.2 \\
\hline \multicolumn{9}{|l|}{$\begin{array}{l}\text { \% time by activity } \\
\text { intensity: }\end{array}$} \\
\hline Sedentary & 48 & $45.6(9.2)$ & 44 & $46.1(8.0)$ & $-0.5(-4.1$ to 3.1$)$ & 0.8 & $-0.7(-3.8$ to 2.4$)$ & 0.7 \\
\hline Light & 48 & $39.9(5.9)$ & 44 & $39.8(5.4)$ & $0.2(-2.2$ to 2.5$)$ & 0.9 & $0.3(-1.7$ to 2.3$)$ & 0.8 \\
\hline Moderate/vigorous & 48 & $14.5(5.5)$ & 44 & $14.2(4.8)$ & $0.3(-1.8$ to 2.5$)$ & 0.8 & 0.4 (-1.6 to 2.4$)$ & 0.7 \\
\hline Diet quality & 56 & $3.8(1.0)$ & 47 & $3.5(1.2)$ & $0.3(-0.03$ to 0.7$)$ & 0.07 & $0.3(0.0$ to 0.6$)$ & 0.05 \\
\hline \multicolumn{9}{|l|}{$\begin{array}{l}\text { Health related } \\
\text { quality of life (health } \\
\text { status): }\end{array}$} \\
\hline Parent report & 51 & $77.5(14.1)$ & 49 & $75.8(13.6)$ & $1.7(-3.8$ to 7.2$)$ & 0.6 & $-0.7(-5.0$ to 3.7$)$ & 0.8 \\
\hline Child report & 51 & $73.0(15.0)$ & 45 & $75.2(14.5)$ & $-2.2(-8.2$ to 3.9$)$ & 0.5 & $-1.9(-7.8$ to 4.0$)$ & 0.5 \\
\hline $\begin{array}{l}\text { Physical } \\
\text { appearance/self } \\
\text { worth, \% positive }\end{array}$ & 51 & 58.7 & 45 & 57.0 & 1.1 (0.6 to 1.8$) \S$ & 0.8 & $1.0(0.6$ to 1.7$) \S$ & $>0.9$ \\
\hline Body dissatisfaction & 51 & $1.3(1.2)$ & 45 & $1.6(1.2)$ & $-0.4(-0.8$ to 0.1$)$ & 0.1 & $-0.3(-0.8$ to 0.2$)$ & 0.3 \\
\hline \multicolumn{9}{|l|}{ Parent $\mathbb{1}$} \\
\hline Mother's BMI & 47 & $28.6(7.6)$ & 46 & $30.2(8.8)$ & $-1.6(-5.0$ to 1.8$)$ & 0.4 & $0.2(-0.8$ to 1.2$)$ & 0.8 \\
\hline Father's BMI & 33 & $29.9(5.2)$ & 35 & $31.5(6.7)$ & $-1.6(-4.5$ to 1.3$)$ & 0.3 & $0.4(-0.9$ to 1.7$)$ & 0.5 \\
\hline \multicolumn{9}{|c|}{ 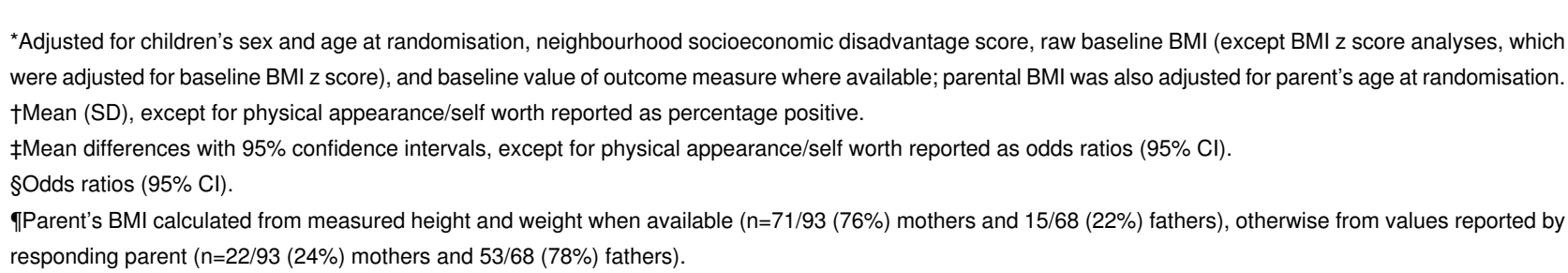 } \\
\hline
\end{tabular}




\begin{tabular}{lllll}
\hline Table 4| Acceptability of intervention to parents and general practitioners & & & \\
& & & \\
& No (\%) & \\
\cline { 3 - 5 } & No & Agree & Neutral & Disagree \\
Parent & & & & \\
\hline Felt understood by: & & & & \\
\hline Specialist clinicians & 46 & $39(85)$ & $6(13)$ & $1(2)$ \\
\hline General practitioner & 47 & $42(89)$ & $2(4)$ & $3(6)$ \\
\hline Understood how to implement goals set by: & & & & \\
\hline Specialist clinicians & 48 & $39(81)$ & $7(15)$ & $2(4)$ \\
\hline General practitioner & 47 & $37(79)$ & $9(19)$ & $1(2)$ \\
\hline Confident of weight change after meeting: & & & & \\
\hline Specialist clinicians & 47 & $34(72)$ & $12(26)$ & $12)$ \\
\hline General practitioner & 47 & $36(77)$ & $9(19)$ & $2(4)$ \\
\hline General practitioners who saw intervention children & & & & \\
\hline Overall "shared care" approach to managing childhood obesity was helpful & 26 & $20(77)$ & $5(19)$ & $1(4)$ \\
\hline Management plan produced by specialist team was helpful & 26 & $23(88)$ & $3(12)$ & $0(0)$ \\
\hline Being able to contact specialist obesity team was helpful & 24 & $16(67)$ & $7(29)$ & $1(4)$ \\
\hline Opening and login into sidebar was easy & 25 & $10(40)$ & $2(8)$ & $13(52)$ \\
\hline "Speed" of sidebar was easy & 25 & $6(24)$ & $2(8)$ & $17(68)$ \\
\hline General useability of sidebar was easy & 24 & $5(21)$ & $7(29)$ & $12(50)$ \\
\hline
\end{tabular}

Excluding general practitioners who reported "not applicable." 


\section{Figures}

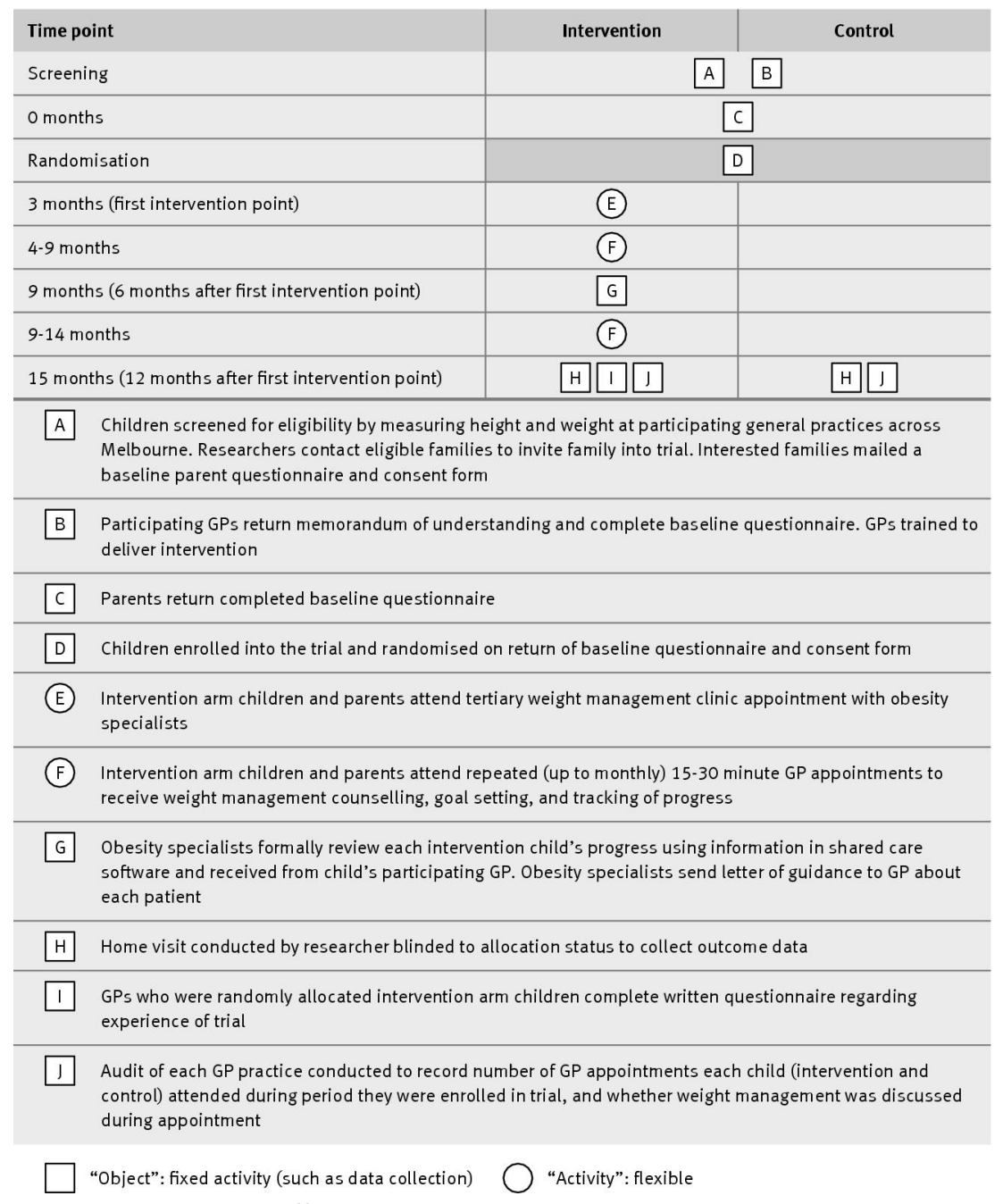

Fig 1 Pictorial diagram ${ }^{39}$ of HopSCOTCH survey and randomised trial. GP=general practitioner 


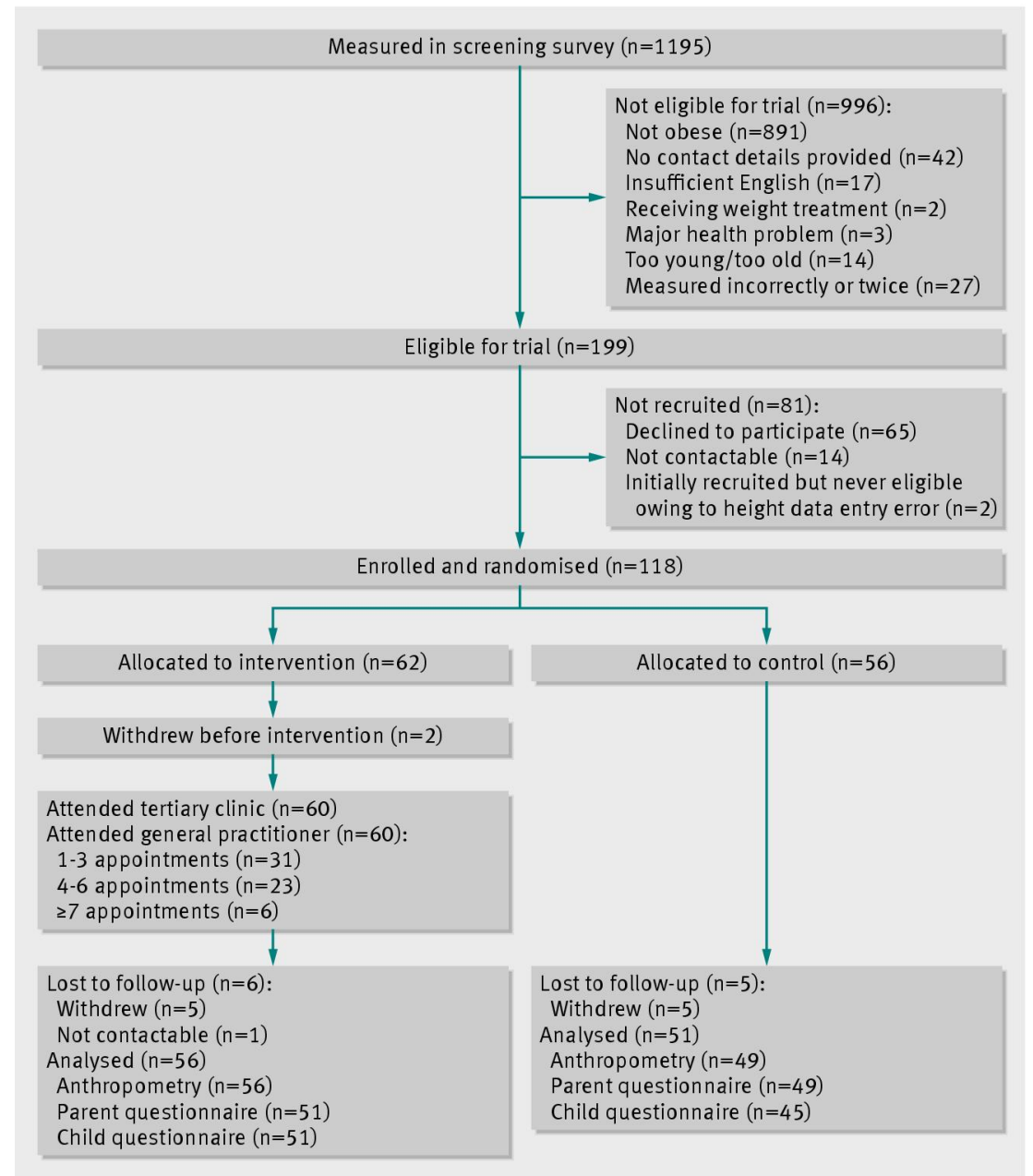

Fig 2 Participant flow chart for HopSCOTCH survey and randomised trial 